\title{
Flight Affects Reproductive Performance and Offspring Development in Oriental Armyworm Mythimna separata (Lepidoptera: Noctuidae)
}

\author{
Abdul Waheed Solangi, Lei Zhang, Yunxia Cheng and Xingfu Jiang* \\ State Key Laboratory for Biology of Plant Diseases and Insect Pests, Institute of \\ Plant Protection, Chinese Academy of Agricultural Sciences, Beijing 100193, China
}

\begin{abstract}
A B S T R A C T
Environment experienced by mothers can influence many of the characteristics of their offspring also apply resource-related maternal effects through differential egg provisioning; we investigated impact of flight on female egg production and longevity in the oriental armyworm Mythimna separata (Walker) and whether this contributed to making difference in considered suite of life-history traits on progeny growth i.e. developmental time, larval and pupal mass. We found that forced flight females had early oviposition with higher fecundities and shorter lifespan, whereas control females had delay oviposition with lower fecundities and longer lifespan. In addition, to these maternal effects, flight stimulated changes in maternal egg provisioning had direct significances on progeny life history traits, progeny from forced flight females had poorer larval and pupal masses but development time was extended. However, offspring from control females had heavier larval and pupal masses with shortened development time. It is possible that an increased of flight during the pre-oviposition and ovipostion period influence the oviposition trend, egg production and lifespan of the next generation in M. separata.
\end{abstract}

\begin{tabular}{l} 
Article Information \\
Received 01 July 018 \\
Revised 02 August 2019 \\
Accepted 06 August 2019 \\
Available online 19 March 2021 \\
Authors' Contribution \\
XFJ designed the experiments. AWS \\
performed the experiments and wrote \\
the article. LZ and YXC analysed the \\
data. \\
Key words \\
\hline M. separata, Flight, Maternal effect, \\
Reproductive plasticity, Offspring life \\
history traits.
\end{tabular}

Received 01 July 018

Revised 02 August 2019

Accepted 06 August 2019

ailable online 19 March 2021

Authors' Contribution

performed texperiments and wrote

the article. $\mathrm{LZ}$ and $\mathrm{YXC}$ analysed the

Key words

M. separata, Flight, Maternal effect,

history traits.

\section{INTRODUCTION}

$\mathrm{M}$ aternal conditions maternal effects

can apply resource-related provisioning, and can significantly influence progeny life history traits (Uller, 2008; Mousseau and Fox, 1998). In insect species, a decline in resources available for reproduction mostly affects the maternal age (Mousseau and Dingle, 1991; Marshall and Uller, 2007; Morag et al., 2011). Flight muscles are the most metabolically active tissue in insects (Harrison and Roberts, 2000) also it (flight) resulted enthusiastically luxurious (Harrison and Roberts, 2000). The oogenesis-flight syndrome hypothesis (Johnson, 1963; Mole and Zera, 1994) forecasts that in flying insect species, physiological constraints caused by an overlap in resources used during flight and during oogenesis results in a resource provisioning trade-off, with rarer resources available for reproductive output (Hughes $e t$ al., 2003; Jervis et al., 2005), also female flight performed during oviposition mainly affect the egg size (Gibbs et al., 2005) including adult females whose inspired for flight laid smaller eggs, variation in development time and also affect larval and pupal masses (Gibbs et al., 2010a, b). This proposes the possible for increased flight during

\footnotetext{
* Corresponding author: xfjiang@ippcaas.cn 0030-9923/2021/0003-0913 \$9.00/0

Copyright 2021 Zoological Society of Pakistan
}

egg laying to make resource-related maternal effects and influence next-generation development (Huang et al., 2005; Gibbs et al., 2010a; Rossiter, 1991). There are good signals in insect species which are predict with regards of life history theory, which propose the deployment of the immune system is energetically expensive and can result in trade-offs with fitness-related behaviors such as; development period larval and pupal masses (Zuk and Stoehr, 2002). The oriental army worm is a nocturnal migratory pest of cereal crops mostly found in Asian countries and Eastern Australia, New Zealand also some Pacific Island with multiple generations per year (Sharma and Sullivan, 2001; Li et al., 1964). The life table of this insect pest is well known in China (Li et al., 1964; Jiang et al., 2014b). Larvae of this polyphagous pest attack on a number of plants including rice, wheat, barley, maize, and sugar cane in China (Zhang et al., 2008a) that annually causes huge crop production and economic losses countrywide (Jiang et al., 2014a). Population dynamics of this noxious species are influenced by many environmental factors (temperature, population, density and flight) (Luo et al., 1995a) from these factors flight is a major factor affecting development, survival rate, and fecundity in M. separata (Jiang et al., 2000). Previous studies on $M$. separata flight propose that; after adult emergence within a couple of days migration begins and it mostly occurs pre reproductively (Luo et al., 1996). The female physiological system connected with flight potential, 
flight muscles growth and flight vigor consumption are improved, whereas reproductive systems like; mating, oogenesis, and egg production generally are affected. This condition is overturned after the flight. Consequently, this trend appears to fit the oogenesis-flight syndrome fairly well (Jiang et al., 2000). The objective of our research was to examine whether after an increased flight during the pre-oviposition period and also during female egg laying influence the oviposition trend, egg production and lifespan of forced flight females and no flight females. Later, our interest was to investigate the effects of parent generation (forced flight and no flight mothers) on their offspring biology (development time, larval and pupal mass). We also observed Relationship between reproductive plasticity, longevity, and oviposition period (days) between offspring traits that are forecast to vary in their average level of female flexibility in Mythmina separata.

\section{MATERIALS AND METHODS}

\section{Stock culture}

Eggs were derived from a large outbred laboratory population of $M$. Separata (placed 300-400 individuals per generation) from Institute of Plant protection, CAAS, Beijing, China. Newly hatched larvae (siblings, 10-20 larvae in a $750 \mathrm{ml}$ jar) were reared, fresh leaves of maize were provided as diet and were raised till pupa and adult emergence in favorable environmental conditions (Temperature; $24-1-{ }^{\circ} \mathrm{C}$; relative humidity; $70 \% \pm 5$ and photoperiod; L14:D10) in insect rearing chamber. After adult emergence we randomly selected 200 females from this laboratory stock and placed separately in netted cages $\left(1 \mathrm{~m}^{3}\right)$, having a $2-\mathrm{ml}$ vial with $5 \%$ honey solution, a virgin male was allowed to the cage and the mating pair was left undistributed for mating (Jiang et al., 2000; Luo, 1995a).

\section{Maternal treatment (forced flight vs. control)}

When females mated successfully were allocated to one of two treatment combination: i) control (no flight) ii) forced flight. Control females placed in their cages without and disturbance or physical pressure and until the first egg was laid, at the first day of oviposition the male was removed from the box and the female was left to continue egg lying up to mortality (Gibbs et al., 2010a). For pilot experiment on day one females from second combinations (forced flight females) were removed from cages and inspired to fly for a short duration of $10 \mathrm{~min}$ at optimum temperature $\left(24-1-{ }^{\circ} \mathrm{C}\right)$, by gently touching their legs with a fine-bristled paint brush each time they alighted (Gibbs et al., 2010b). When forced flight tested, the females (forced flight females) were brought for copulation in their cages till the first day of egg laying. When the first egg was laid, the male was removed from the cage and the female was left undisturbed in the cage to continue egg lying. On days 2-4-6 of oviposition, the flight treatment was repeated so that in total each experimental female was forced to fly four times (Gibbs et al., 2010a). A number of female forced to fly were $n=20$ and control females $n=20$ experimental females were set up, with five replications of each treatment. After successful mating of these females, they laid viable eggs. Each day, the fresh honeydew solution was provided to mothers of both combinations as adult diet. Daily egg production up to female mortality was counted and considered as total female fecundity (Jiang et al., 2000). Adult life span investigated and calculated as long as the female was alive (Luo et al., 1995a; Jiang et al., 2000).

\section{Offspring development}

The intention of the study was to investigate whether maternal regimes affect the considered life history traits of progeny. To control for possible day effects, individual eggs that were laid by females on the same day (day of oviposition) were used to examine offspring performance.

For investigation of offspring life history suites, the eggs laid by mothers from $1^{\text {st }}$ to $8^{\text {th }}$ day of oviposition were added in the analyses. Development time of offspring was investigated for all individuals as an embryonic and post-embryonic development from per combination. For measurements of larval mass $\left(5^{\text {th }}\right.$ and $6^{\text {th }}$ instars $)$ and pupal mass (three-day-old pupae) from all regimes were weighed on an electronic balance (A and D, Tokyo, Japan), and isolated in individual $48 \mathrm{~cm}^{3}$ plastic boxes (Luo et al., 1996; Jiang et al., 2010; Gibbs et al., 2005).

\section{Statistical analysis}

For investigation of proposed study, the multivariate equivalent of a t-test the Hoteling's $\mathrm{t}^{2}$ test (to test mean differences between two groups) was used. This test is same to a multivariate analysis of variance with a twolevel factor. In biological terms, this test examines whether both treatment groups are governed by the same kind of trade-offs on a particular day and across days. We used average value from all replicated data of every day, to test the relationship between 'female fecundity, oviposition period and longevity (days)' also 'offspring life history traits' using the Originpro 2015. ANCOVAS were done to determine the influence of maternal treatment (forced flight versus control) and their interaction with off spring development time, larval and pupal masses. Only significant interaction terms were used in the ANCOVA. All statistical procedures performed using through SPSS advanced software (IBM 21 version). 


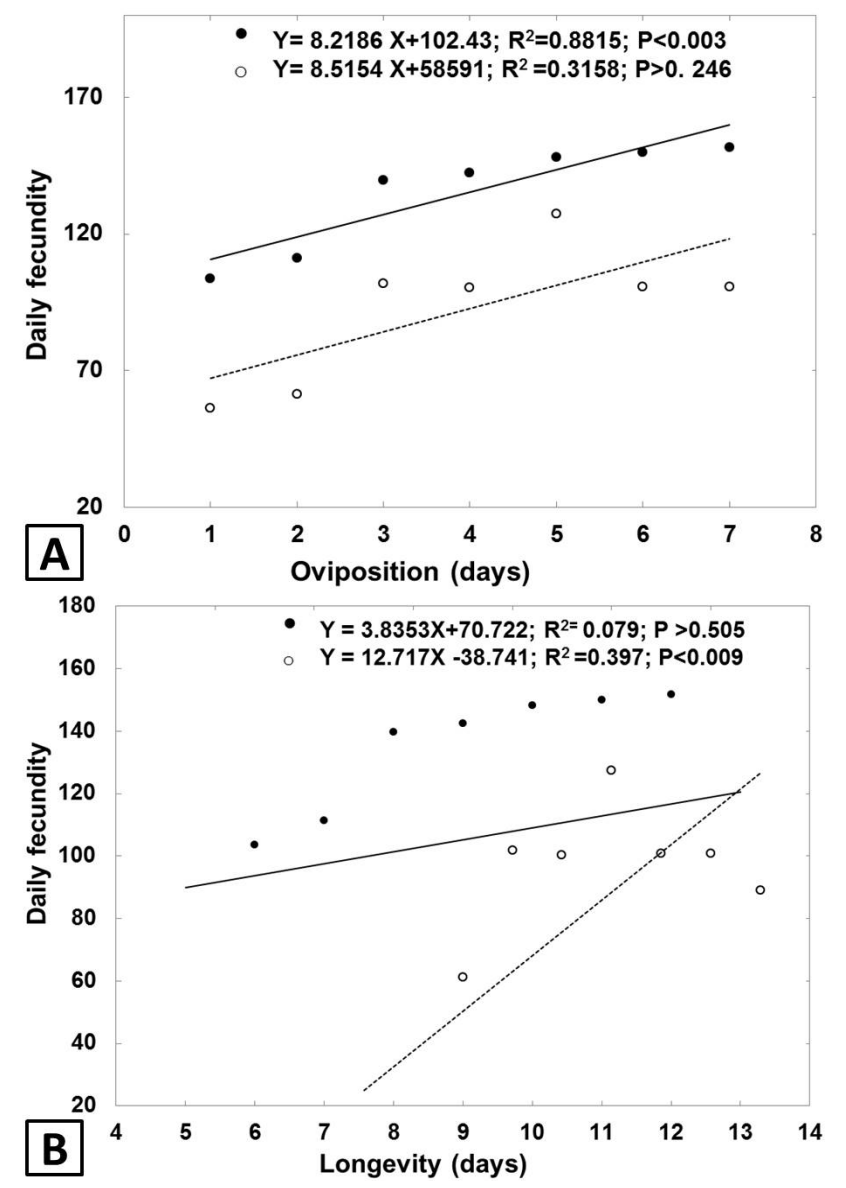

Fig. 1. Regression between daily fecundity and oviposition (days) (A), regression between longevity (days) and mean daily fecundity (B), from the forced flight (filled circle) and control (open circle) in M. separata females.

\section{RESULTS}

\section{Maternal reproductive plasticity}

To examine that control and forced flight females made a significant difference between physiological tradeoffs in total numbers of eggs and day of oviposition (1-7 days) were affected by flight. Control and forced flight females displayed a different trend of egg lying at the start of oviposition, at $1^{\text {st }}, 2^{\text {nd }}$ and $3^{\text {rd }}$ day of oviposition females from forced flight laid more eggs than control females with significant difference $(\mathrm{t}=6.06 ; \mathrm{P}=<0.0001)$. The maximum per day egg production was observed at forced flight than at control females, later they increase egg production from the $4^{\text {th }}$ day of oviposition to onwards, but less than forced flight females. The mothers forced to flight reliably laid more eggs than other mothers on a specific day and across the day. Overall, highest lifetime egg production from forced flight females was recorded than at control females (mean \pm S.E, forced flight $=949.68 \pm 26.89$ eggs, mean \pm S.E, control $=651.89 \pm 35.86$ eggs). There was a positive and significant relationship between mean daily fecundity and oviposition period (days) with forced flight mothers, whereas control mothers had and not a significant relationship (Fig. 1A).

\section{Longevity (forced flight and control females)}

Adult lifespan showed a significant difference between both treatments; forced fly females had significantly shorter lifespan than control females (mean \pm S.E, forced flight $=11.06 \pm 0.32$ days, mean \pm S.E, control $=12.04 \pm 0.27$ days). There were significant difference between both treatments $(\mathrm{t}=3.13 ; \quad \mathrm{P}<0.003)$. Relationship between fecundity and longevity (days) from forced flight females were significant and positive, but were negative and not a significant relationship between control females, respectively (Fig. 1B).

\section{Offspring development time}

Day of oviposition significantly explained variation in offspring developmental time; Correlation shows eggs from forced females whose laid eggs from $1^{\text {st }}$ to $3^{\text {rd }}$ day, the developmental time was much longer than $4^{\text {th }}$ day to onwards. Whereas, control females lay eggs on $1^{\text {st }}$ to $3^{\text {rd }}$ day of oviposition the developmental time was shortened, but it increases oviposition from $4^{\text {th }}$ to onwards. Overall, mean developmental time was longer at offspring from forced flight and then from control (mean \pm S.E, forced flight= $44.07 \pm 0.17$ days, mean \pm S.E, control $=42.24 \pm 0.21$ days) with significant differences $(\mathrm{t}=6.58 ; \mathrm{P}<0.0001)$. There was a positive and significant relationship between offspring development time and oviposition (days) from forced flight mothers. Whereas, negative and not a significant relationship between control mothers were observed, as well as significant interaction (Table I; Fig. 2A).

Table I.- Effects of maternal treatment (forced flight and control mothers) on considered life history traits of their offspring in M. separata.

\begin{tabular}{lcccc}
\hline Trait / Factor & df & MS & F-ratio & P \\
\hline Development time & & & & \\
Maternal treatment & 1 & 15.46 & 28.83 & $<0.005$ \\
Interaction & 1 & 0.22 & 16.35 & $<0.001$ \\
Larval weight & & & & \\
Maternal treatment & 1 & 365.71 & 13.6 & $<0.003$ \\
Interaction & 1 & 836.65 & 15.6 & $<0.002$ \\
Pupal weight & & & & \\
Maternal treatment & 1 & 1547.24 & 1.57 & $<0.006$ \\
Interaction & 1 & 8618.04 & 30.80 & $<0.013$ \\
\hline
\end{tabular}




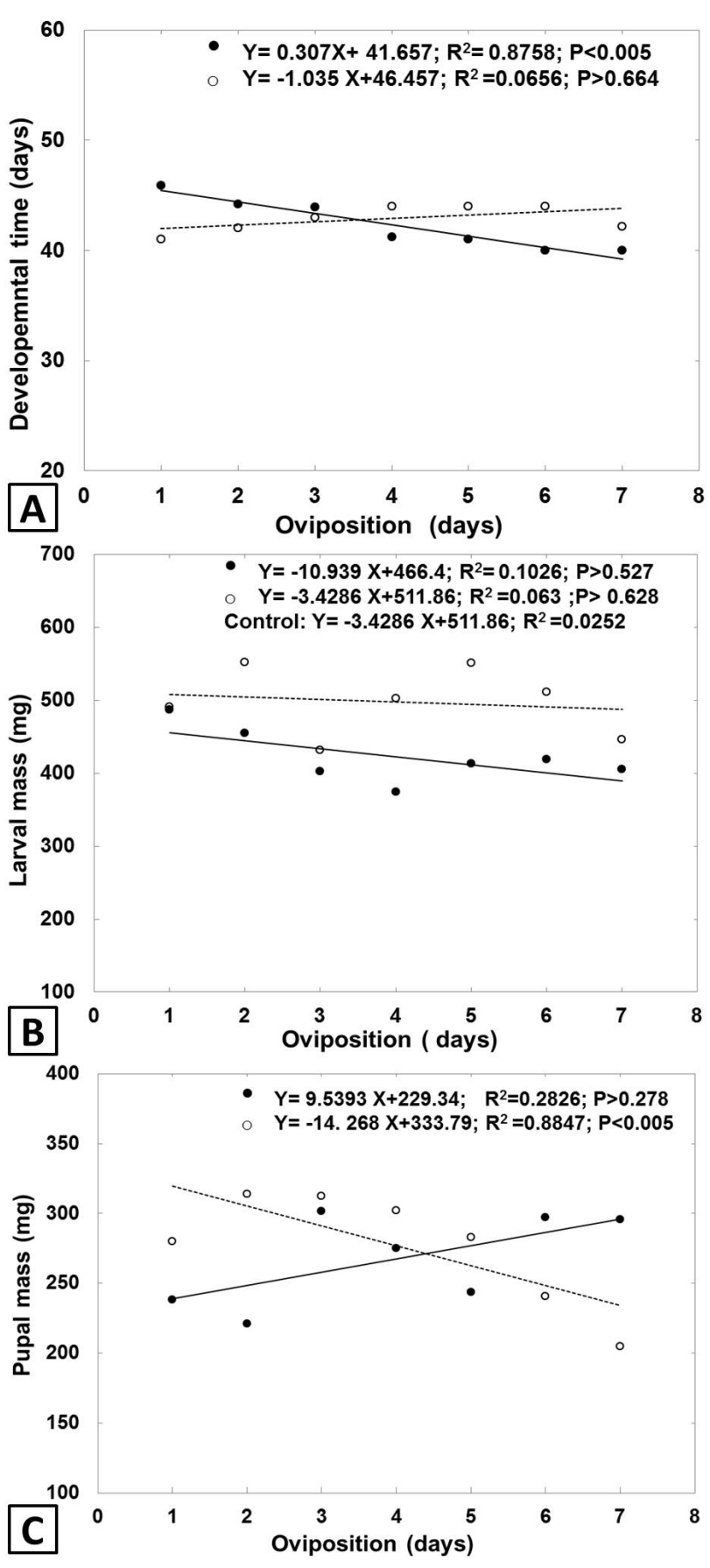

Fig. 2. Regression between offspring development time (days) and oviposition (days) (A), offspring larval mass (mg) and oviposition (days) (B), offspring pupal mass (mg) and oviposition (days) (C) from forced flight (filled circle) and control (open circle) in $M$. separata females.

\section{Offspring larval mass ( $\mathrm{mg}$ )}

Forced flight mothers significantly affect the larval mass (mg) of their offspring; larvae emerged from control females on $2^{\text {nd }}, 4^{\text {th }}$ and $6^{\text {th }}$ day of oviposition significantly heavier. However, larvae hatch from forced flight mothers from $1^{\text {st }}$ and $2^{\text {nd }}$ day of oviposition was heavier, but weight was decreased from $3^{\text {rd }}$ to onwards oviposition days. Overall, larval mass subsequently heavier offspring from a control than at forced flight mothers (mean \pm S.E, control $=$ 499.37 \pm 11.6 , mean \pm S.E, forced flight $=424.15 \pm 13.18)$ with significant difference $(\mathrm{t}=4.28 ; \mathrm{P}<0.001)$. It was observed that there was a negative relationship between offspring larval mass (mg) and oviposition (days) from forced flight and control mothers with significant interaction (Table I; Fig. 2B).

\section{Offspring pupal mass ( $\mathrm{mg}$ )}

Pupal mass of offspring was significantly heavier at control than at forced flight mothers (mean \pm S.E, control $=300.68 \pm 4.59$, mean \pm S.E, forced flight $=249.33 \pm 5.84$ ), both combinations from $3^{\text {rd }}$ and $4^{\text {th }}$ day of oviposition pupal mass heavier than other days. However, significant difference between both treatments was observed $(\mathrm{t}=6.90$; $\mathrm{P}=<0.0001$ ). Correlation shows there were negative but significant relationship between pupal mass and oviposition days from control mothers. Whereas, offspring from forced flight mothers displayed negative and not a significant relationship (Fig. 2C), also significant interactions were observed between both treatments (Table I).

\section{DISCUSSION}

The current findings emphasis on physiological trade-offs after flight and reproduction in M. separata, and explores the potential for the transmission of flight-induced non-genetic maternal effects. In this study, a substantial intensive flight was performed by females and were stimulated for a flight several times across the oviposition period, as in previous studies flight was performed by a female adult (Gibbs et al., 2010a, b; Hughes et al., 2003, Jervis et al., 2005). We demonstrated that forced flight females displayed highest lifetime egg production on $2^{\text {nd }}$ to $4^{\text {th }}$ day of oviposition (Wiklund and Persson, 1983) and have a significantly maximum egg production, however egg production was dropped with maternal age as previously reported and hypothesized in P. aegeria (Gibbs et al., 2010a; Hughes et al., 2003). Pre-oviposition period of $M$. separata females are most sensitive to environmental signals that arbitrate female egg production and can influence adults lifespan, we found forced flight females had early oviposition with higher fecundities and shorter lifespan, whereas control females have delay oviposition with lower fecundities and longer lifespan (Steigenga et al., 2005; Gibbs et al., 2010b). Conflicting to findings on other insect species, we examined that offspring from older 
mothers did not differ in survival during the larval stages/ development of offspring (Geister et al., 2008; Gibbs et al., 2010a) development time (Benton et al., 2001) or pupal mass (Rossiter , 1999). Our findings determine that flight significantly affect offspring life history traits, eggs laid by females forced to fly had significantly smaller larval and pupal masses with longer development time (Bernardo, 1996). Whereas, offspring from control females had shorter developmental time with heavier larval and pupal masses, this variation in results shows the potential for flight-induced changes in maternal egg provisioning to continue applying effects later in progeny growth (Gibbs et al., 2010a, b). The forced flight period appears very short, as compared with field or laboratory tethered flight evaluations from previous studies of a female was tested in M. separata by Jiang and Luo (2005), Li and Luo (1999) and Jiang et al. (2005). What we found, although lowest flight duration during egg-laying may influence female egg production, longevity and offspring performance (Benton et al., 2005). Moreover, during the flight, females want to take landing and rest but continue to push up repetition for flight and avoid landing it is most energetically expensive kind of acceleration (Mark et al., 2000). This study revealed that; flight duration and nature of flight test (after adult emergence) together apply a significant influence on offspring fitness. Marshall and Uller (2007) also reported a current analysis cautioned against using 'snapshot' experimental studies to examine whether changes in maternal investment in offspring may have an adaptive significance. Also, our findings obviously expose the cross-generational effect and highlight the significance for the establishment of several behaviors in new findings, because the effects are most probably trait-related. During our findings, $M$. seaprata flights negatively influence on offspring life history traits. For this noxious insect pest, this study is the first to prove that flight before and during egg-laying may influence mothers lifetime egg production as well as the progeny growth.

\section{CONCLUSION}

It is concluded that flight performed before or during female egg-laying may apply maternal fitness effect in M. separata. Also, it was observed characteristics of the progeny affected by the maternal environment in our study. This could have important consequences for population dynamics, mostly in agricultural fields. $M$. separata has fascinated attention in studies of distribution and dispersal in response to climate changes, and in studies of evolutionary trade-offs at both increasing range margins and in relation to habitat fragmentation.

\section{ACKNOWLEDGMENT}

The present study funded by National Department of Public Benefit Research Foundation (201403031), China Agriculture Research System-Green Manure (CARS-22), and National Key R\&D Program of China (2017YFD0201802, 2017YFD0201701), National Natural Science Foundation of China $(31672019,31371947)$ and Beijing Natural Science Foundation (6172030).

\section{Statement of conflict of interest}

The authors declare no conflict of interest.

\section{REFERENCES}

Benton, T.G., Ranta, E., Kaitala, V. and Beckerman, A.P., 2001. Maternal effects and the stability of population dynamics in noisy environments. $J$. Anim. Ecol., 70: 590-599. https://doi.org/10.1046/ j.1365-2656.2001.00527.x

Benton, T.G., Plaistow, S.J., Beckerman, A.P., Lapsley, C.T. and Little, J.S., 2005. Changes in maternal investment in eggs can affect population dynamics. Proc. R. Soc. Lond. B, 272: 3081. https://doi. org/10.1098/rspb.2005.3081

Bernardo, J., 1996. The particular maternal effect of pro pagule size, especially egg size: Patterns, models, quality of evidence and interpretations. Am. Zool., 36: 216-236. https://doi.org/10.1093/icb/36.2.216

Gibbs, M., Lace, L.A., Jones, M.J. and Moore, A.J., 2005. Egg size-number trade-off and a decline in oviposition site choice quality: Female Pararge aegeria butterflies pay a cost of having males present at oviposition. J. Insect Sci., 5: 39-45. https://doi.org/10.1093/jis/5.1.39

Gibbs, M., Breuker, C.J. and Van, D.H., 2010a. Flight during oviposition reduces maternal egg provisioning and influences offspring development in Pararge aegeria (L.). Physiol. Ent., 35: 29-39. https://doi.org/10.1111/j.1365-3032.2009.00706.x

Gibbs, M., Van, D.H. and Karlsson, B., 2010b. Reproductive plasticity, ovarian dynamics and maternal effects in response to temperature and flight in Pararge aegeria. J. Insect Physiol. 56: $\quad 1275-1283$. https://doi.org/10.1016/j. jinsphys.2010.04.009

Geister, T.L., Lorenz, M.W., Meyering-Vos, M., Hoffmann, K.H. and Fischer, K., 2008. Effects of temperature on reproductive output, egg provisioning, juvenile hormone and vitellogenin titres in the butterfly Bicyclus anynana. J. Insect Physiol., 54: 1253-1260. https://doi.org/10.1016/j. 
jinsphys.2008.06.002

Huang, C.C., Yang, R.L., Lee, H.J. and Horng, S.B., 2005. Beyond fecundity and longevity: Trade-offs between reproduction and survival mediated by behavioral responses of the seed beetle, Callosobruchus maculatus. Physiol. Ent., 30: 381-387. https://doi.org/10.1111/j.13653032.2005.00474.x

Hughes, C.L., Hill, J.K. and Dytham, C., 2003. Evolutionary trade-offs between reproduction and dispersal in populations at expanding range boundaries. Proc. R. Soc. Lond. B, 270: S147-S150. https://doi.org/10.1098/rsbl.2003.0049

Harrison, J.F. and Roberts, S.P., 2000. Flight respiration and energetics. Annu. Rev. Physiol., 62: 179-205. https://doi.org/10.1146/annurev.physiol.62.1.179

Jervis, M.A., Boggs, C.L. and Ferns, P.N., 2005. Egg maturation strategy and its associated trade-offs: A synthesis focusing on Lepidoptera. Ecol. Ent., 56: 145-150.

Jiang, X.F., Luo, L.Z. and Hu, Y., 2000. Influence of rearing temperature on flight and reproductive capacity of adult oriental armyworm, Mythimna separata (Walker). Acta Ecol. Sin. 20: 288-292.

Jiang, X.F. and Luo, L.Z., 2005. Comparison of behavioral and physiological characteristics between the emigrant and immigrant populations of the oriental armyworm, Mythimna separata (Walker). Acta entomol. Sin. 48: 61-67.

Jiang, X.F., Luo, L.Z. and Hu, Y., 2005. Genetic characteristics of pre-oviposition period in the oriental armyworm Mythimna separata (Walker). Acta Ecol. Sin., 25: 68-72.

Jiang, X.F., Zhang, L., Cheng, Y.X. and Luo, L.Z., 2014a. Current status and trends in research on the oriental armyworm Mythimna separata (Walker) in China. Chinese J. appl. Ent., 51: 1444-1449.

Jiang, Y.Y., Li, G., Zeng, G.J. and Liu, J., 2014 b. Population dynamics of the armyworm in China: a view of the past 60 years research. Chinese J. appl. Ent., 51: 890-898.

Johnson, C.G., 1963. Physiological factors in insect migration by flight. Nature, 41: 125-129.

Li, G.B., Wang, H.X. and Hu, W.X., 1964. Route of the seasonal migration of the oriental armyworm moth in the eastern part of China as indicated by a threeyear result of releasing and recapturing of marked moths. Acta Phytophyl. Sin., 3: 101-110.

Li, K.B. and Luo, L.Z., 1999. Activities of enzymes in the Bight muscle of pupal and adult oriental armyworm, Mythimna separata (Walker). Acta entomol. Sin., 42: 37-43.
Luo, L.Z., Li, B.G., Cao, Y.Z. and Hu, Y., 1995a. The influence of larval rearing density on flight capacity and fecundity of adult oriental army worm, Mythimna separata (Walker). Acta entomol. Sin., 38: $38-45$.

Luo, L.Z. and Li, G.B., 1996. Ultrastructure of the flight muscle of adult armyworm, Mythimna separata (Walker). Acta entomol. Sin., 39: 141-148.

Mark, C.E. and Joseph, S.E., 2000. Maternal effects on gypsy moth (Lepidoptera: Lymantriidae) population dynamics: A field experiment. Environ. Ent., 29: 476-488. https://doi.org/10.1603/0046225X-29.3.476

Marshall, D.J. and Uller, T., 2007. When is a maternal effect adaptive? Oecologia, 116: 1957-1966. https://doi.org/10.1111/j.2007.0030-1299.16203.x

Mousseau, T.A. and Dingle, H., 1991. Maternal effects in insect life histories. Annu. Rev. Ent. 36: 511-534. https://doi.org/10.1146/annurev. en.36.010191.002455

Mousseau, T.A. and Fox, C.W., 1998. The adaptive significance of maternal effects. Trends Ecol. Evol., 13: 403-407. https://doi.org/10.1016/S01695347(98)01472-4

Mole, S. and Zera, A.J., 1994. Differential resource consumption obviates a potential flight fecundity trade-off in the sand cricket (Gryllusfirmus). Funct. Ecol., 8: 573-580. https://doi.org/10.2307/2389917

Morag, N., Keasar, T., Harari, A. and Bouskila, A., 2011. Trans-generational effects of maternal rearing density on offspring development time in a parasitoid wasp. Physiol. Ent., 40: 1-5. https://doi. org/10.1111/j.1365-3032.2011.00781.x

Rossiter, M.C., 1991. Maternal effects generate variation in life-history-Consequences of egg weight plasticity in the gypsy moth. Funct. Ecol., 5: 386-393. https://doi.org/10.2307/2389810

Sharma, H.C. and Sullivan, D.J., 2001. Screening for plant resistance to Oriental armyworm, Mythimna separata (Lepidoptera: Noctuidae) in Pearl Millet, Pennisetum glaucum. J. Agric. Urban Ent., 17: 125-134.

Steigenga, M.J., Zwaan, B.J., Brakefield, P.M. and Fischer, K., 2005. The evolutionary genetics of egg size plasticity in a butterfly. J. Evol. Biol., 18: 281-289. https://doi.org/10.1111/j.14209101.2004.00855.x

Uller, T., 2008. Developmental plasticity and the evolution of parental effects. Trends Ecol. Evol., 23: 432-438. https://doi.org/10.1016/j.tree.2008.04.005

Wiklund, C. and Persson, B., 1983. Fecundity, and the relation of egg weight variation to offspring 
fitness in the speckled wood butterfly Pararge aegeria, or why don't butterfly females lay more eggs? Oecologia, 40: 53-63. https://doi. org/10.2307/3544198

Zhang, L., Jiang, X.F. and Luo, L.Z., 2008. Determination of sensitive stage for switching migrant oriental armyworms, Mythimna separata (Walker), into residents. Environ. Ent., 37: 1389-1395. https://doi. org/10.1603/0046-225X-37.6.1389

Zuk, M. and Stoehr, A.M., 2002. Immune defense and host life history. Nature, 160: S9-S22. https://doi. org/10.1086/342131 